\title{
Orthocyanosis: a sign of pulmonary arteriovenous malformation
}

\section{VH HOEPPNER}

\section{From the Department of Medicine, University Hospital, Saskatoon, Saskatchewan, Canada}

Normally the arterial oxygen tension $\left(\mathrm{PaO}_{2}\right)$ remains the same or rises with the change from the supine to the upright position.' Several patients showing the opposite phenomenon (orthodeoxia) have been reported, some with a pulmonary arteriovenous malformation. ${ }^{2}$

While cyanosis is a recognised feature of pulmonary arteriovenous malformation, ${ }^{34}$ our patient is of interest because she had cyanosis when she was upright but not when she was supine (orthocyanosis).

\section{Case report}

A 17-year-old girl was referred for investigation of polycythaemia. She had had no dyspnoea, haemoptysis, chest pain, epistaxis, or melaena. When examined supine her blood pressure was $100 / 70 \mathrm{~mm} \mathrm{Hg}$, pulse 56 beats/min, respiratory rate $12 / \mathrm{min}$, and temperature $37^{\circ} \mathrm{C}$. She did not have cyanosis, clubbing, or telangiectasis. Examination of the lungs showed nothing abnormal. The heart size and sounds were normal. A systolic bruit was easily heard over the left anterolateral part of the chest. An inspiration greater than tidal volume increased the systolic intensity of the bruit. Examination showed cyanosis when she was upright. The bruit increased in intensity and became continuous with systolic accentuation.

The haemoglobin concentration was $16 \cdot 7 \mathrm{~g} / 100 \mathrm{ml}$ with a haematocrit of $47 \%$. The electrocardiogram was normal. The chest radiograph showed a $4.5 \times 5 \cdot 0 \mathrm{~cm}$ non-homogeneous mass in the left lower lobe obliterating part of the anterior hemidiaphragm. Blood gases were obtained with the patient in the supine and upright positions having $21 \%$ and $100 \%$ oxygen. The results are recorded in the table. The shunt fraction was obtained with Benatar's virtual isoshunt lines. ${ }^{5}$ Haemodynamic data from catheterisation of the left and right side of the heart showed normal pulmonary artery pressure, pulmonary resistance, and cardiac output, with pulmonary flow equal to systemic flow. A pulmonary angiogram showed an arteriovenous malformation in the left lower lobe (fig 1). An uneventful lobectomy was carried out. After surgery cyanosis was no longer observed and the blood gases showed improved gas exchange (table).

\section{Discussion}

In pulmonary disease the $\mathrm{PaO}_{2}$ most commonly rises in the upright position above its level in the supine position. In contrast. orthodeoxia has been observed in congenital heart disease with right-to-left shunt. The explanation for both phenomena has been well documented. ' In these patients the cyanosis present in the

Address for reprint requests: Dr VH Hoeppner. Department of Medicine. University Hospital. Saskatoon. Saskatchewan. Canada.

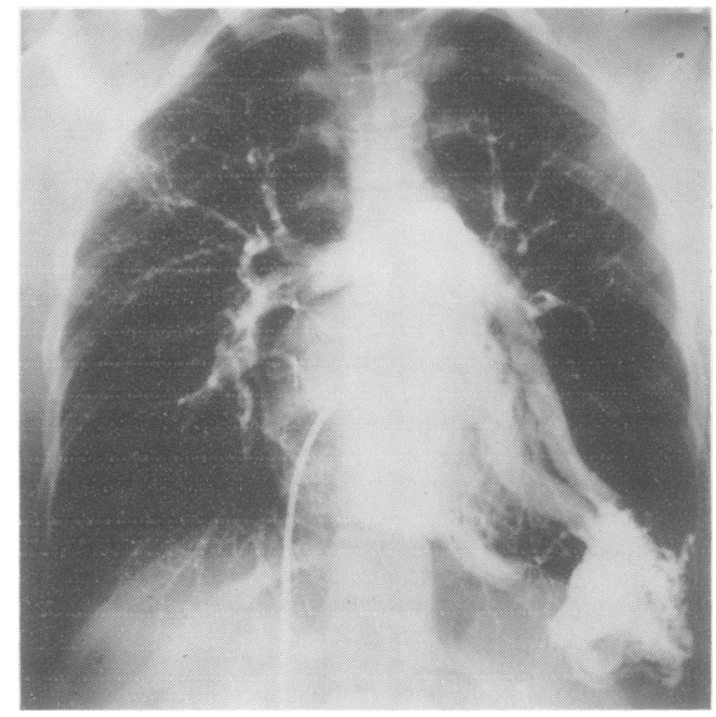

Fig 1 Pulmonary angiogram showing the malformation in the left lower lobe (patient in supine position).

Arterial blood gases before and after surgery

\begin{tabular}{|c|c|c|c|c|c|c|c|}
\hline \multirow[b]{3}{*}{$\mathrm{F}_{1} \mathrm{O}_{2}$} & \multicolumn{4}{|c|}{ Before surgery } & \multicolumn{3}{|c|}{ After surgery } \\
\hline & \multicolumn{2}{|c|}{ Upright } & \multicolumn{2}{|c|}{ Supine } & \multicolumn{2}{|c|}{ Upright } & \multirow{2}{*}{$\frac{\text { Supine }}{0 \cdot 2 l}$} \\
\hline & 0.21 & $1 \cdot 0$ & $0 \cdot 21$ & $1 \cdot 0$ & $0 \cdot 21$ & 1.9 & \\
\hline$\overline{\mathrm{pH}}$ & $7 \cdot 43$ & $7 \cdot 42$ & $7 \cdot 42$ & $7 \cdot 43$ & $7 \cdot 42$ & $7 \cdot 43$ & $7 \cdot 42$ \\
\hline $\mathrm{PaCO}_{2} \mathrm{~mm} \mathrm{Hg}$ & 25 & 28 & 34 & 30 & 38 & 34 & 38 \\
\hline $\mathrm{PaO}_{2}=\mathrm{mm} \mathrm{Hg}$ & 45 & 52 & 59 & 136 & 82 & 500 & 83 \\
\hline $\mathrm{SaO}_{2} \%$ & 83 & 88 & 91 & 99 & 96 & 100 & 96 \\
\hline Qs & & $0 \cdot 45$ & & $0 \cdot 23$ & & $0 \cdot 08$ & \\
\hline
\end{tabular}

upright position has been diminished or reversed in the supine position. More recently orthodeoxia has been reported in true $\mathrm{N}$ vascular lung shunts, several due to pulmonary arteriovenous malformation. ${ }^{2}$

The pathophysiology of orthodeoxia in lung vascular shunts is quite different from that in right-to-left intracardiac shunts. The lung has a two-compartment circulation, the alveolar or small@ vessel compartment and the extra-alveolar or large vesselcompartment. $^{78}$ With lung inflation, resistance rises in the $\frac{T}{0}$ alveolar vessels and falls in the extra-alveolar vessels. With deflation, the opposite occurs. This is due to the regional determinants of blood flow - namely, arterial, alveolar, and venous pressure. ${ }^{9}$ 


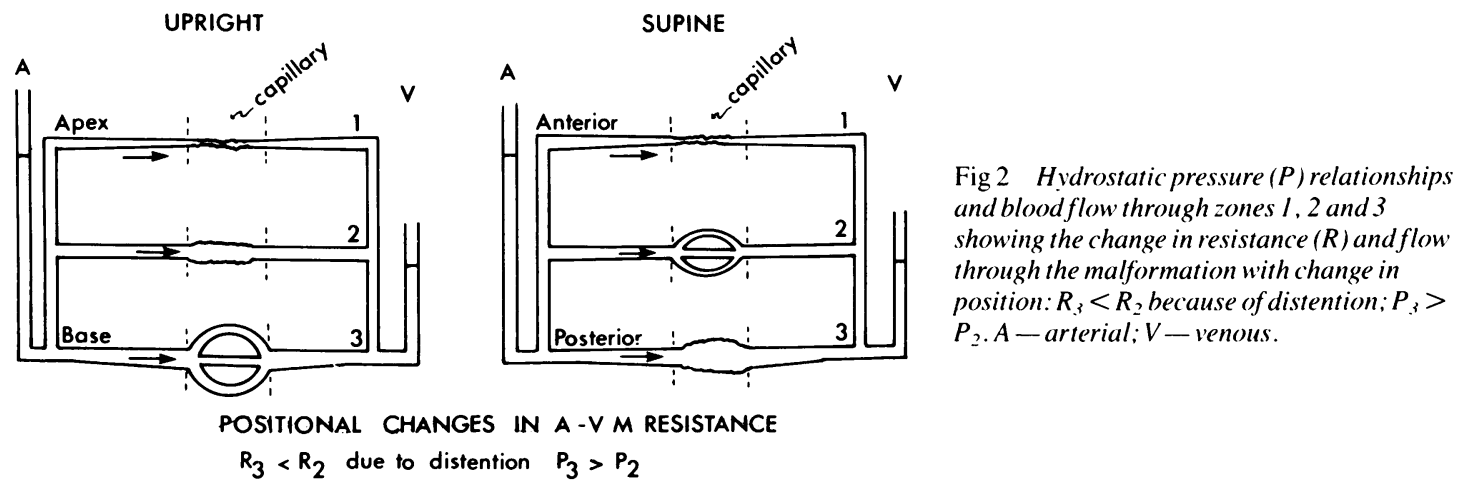

In the arteriovenous malformation the vessels act as extra-alveolar vessels. ${ }^{310}$ Since they are not in series with alveolar vessels, the flow through them for a given pulmonary arteriovenous pressure difference is determined by the absolute hydrostatic distending pressure $(\mathrm{P})$ at a given lung volume and the distending forces of the surrounding lung at varying lung volumes. 710

With our patient in the supine position the arteriovenous malformation was at the level of the heart. probably in zone 2 (fig 2 ) and the shunt was $23 \%$. When she was breathing room air the $\mathrm{PaO}_{2}$ was $59 \mathrm{~mm} \mathrm{Hg}$ and no cyanosis was noted. When she was upright the arteriovenous malformation was below the level of the heart, probably in zone 3 . It exerted less resistance to blood flow in the upright position because the distending $\mathrm{P}_{3}$ was greater than $\mathrm{P}_{2}$ (fig 2). Furthermore, the resistance in the alveolar vessels was probably higher in the upright position than in the supine position because of a predicted increase in functional residual capacity. ${ }^{11}$ With resistance probably increased in the alveolar vessels and diminished in the arteriovenous malformation when she was upright flow through it increased. Accordingly, the shunt increased to $45 \%$, the $\mathrm{PaO})_{2}$ fell to $45 \mathrm{~mm} \mathrm{Hg}$, and cyanosis become evident. With further increase in lung volume during inspiration. further increase in flow through the arteriovenous malformation would be expected. This is the probable explanation for the increase in the intensity of the bruit during inspiration.

Orthocyanosis differs from orthodeoxia in the degree of artertial oxygen desaturation. This case is of interest for this reason. The arteriovenous malformation. although congenital. generally does not become clinically manifest until the third decade. ${ }^{3}$ It results from malformation of arteries and veins from a common capillary plexus. It is thin walled and gradually distends with time owing to constant exposure to arterial pressures. ${ }^{3}$ It has been shown to increase further in size even after it becomes clinically evident. ${ }^{+}$In the evolution of arteriovenous malformation orthocyanosis therefore may be a transient sign of a long-term dynamic range of clinical manifestations. These include mild hypoxaemia with orthodeoxia, moderate hypoxaemia with orthocyanosis, and severe hypoxaemia with cyanosis in both the upright and the supine positions.

\section{References}

'Craig DB, Wahba WM, Don HF, Constance JG, Becklake M. "Closing volume" and its relationship to gas exchange in seated and supine positions. J Appl Phvsiol 1971:31:717-21.

2 Robin ED, Laman D, Horn BR, Theodore J. Platypnea related to or thodeoxia caused by true vascular lung shunts. N Engl J Med 1976;294:941-3.

${ }^{3}$ Moyer JH, Glantz G, Brest AN. Pulmonary arteriovenous fistulas: physiologic and clinical considerations. Am J Med 1962:32:417-35.

${ }^{4}$ Dines DE, Arms RA, Bernatz PE, Gomes MR. Pulmonary arteriovenous fistulas. Mavo Clin Proc 1974:49:460-5.

${ }^{5}$ Benatar SR, Hewlett AM, Nunn JF. The use of isoshunt lines for control of oxygen therapy. Br J Anaesth 1973;45:711-8.

${ }^{6}$ Lurie RP. Postural effects in tetralogy of Fallot. Am J Med 1953;15:297-306.

${ }^{7}$ Howell JBL, Permutt S, Proctor DF, Ritchy RL. Effect of inflation of the lung on different parts of the pulmonary vascular bed. J Appl Physiol 1961;16:71-6.

${ }^{8}$ Mead J, Whittenberger JL. Lung inflation and hemodynamics. In: Fenn WO. Rahn H, eds. Handbook of physiology: Section 3: Respiration. Vol 1. Washington DC: American Physiological Society, 1964;477-86.

"West JB, Dollery CT. Distribution of blood flow and the pressure-flow relations of the whole lung. J Appl Phvsiol 1965:20:175-83.

${ }^{10}$ Huseby JS, Culver BH, Butler J. Pulmonary arteriovenous fistulas: increase in shunt at high lung volume. Am Rev Respir Dis 1977;115:229-32. 